\title{
Modelling the Behavioural Response to Congestion Pricing in Dhaka, Bangladesh
}

\author{
Md. Abu Bakkar Siddique ${ }^{1}$ Charisma F. Choudhury ${ }^{2}$ (I)
}

Received: 23 April 2016 / Accepted: 4 September 2017 / Published online: 15 September 2017

(C) The Author(s) 2017. This article is an open access publication

\begin{abstract}
Dhaka, the capital city of Bangladesh and the home of more than 15 million people, is subjected to severe traffic congestion on a regular basis resulting in lost productivity, fuel wastage, commuter frustration and environmental degradation. The problem is getting more acute day by day due to alarming increase in car usage. According to Bangladesh Road Transport Authority, the number of newly registered private cars per year in the city has more than quadrupled between 2004 and 2015. Congestion pricing schemes, which have been successful in many parts of the world, have a good potential to minimize the number of cars on the roads and reduce traffic congestion in Dhaka. This paper investigates the potential response to congestion pricing in Dhaka using stated preference surveys where users are presented with hypothetical choice scenarios involving varying amounts of congestion charges and travel time savings alongside improved public transport options. Two case studies have been conducted in this regard focusing on shopping and work trips respectively. Discrete choice models have been developed to model the sensitivity towards congestion pricing and to quantify the potential effectiveness of this measure in different trip contexts. Results indicate that car users, especially those having lower incomes (less than $50,000 \mathrm{BDT} / \mathrm{month}$ ), have significant sensitivity towards congestion charge and have a substantial chance of shifting
\end{abstract}

Charisma F. Choudhury

cfc@alum.mit.edu

Md. Abu Bakkar Siddique

sohag024@gmail.com

1 Department of Civil Engineering, Bangladesh University of Engineering and Technology, Dhaka 1000, Bangladesh

2 Institute for Transport Studies, University of Leeds, Leeds, UK to improved public transport and/or park-and-ride facilities. The findings of the study can help in formulating effective congestion reduction policies in Dhaka.

Keywords Congestion pricing · Park and ride · Developing country $\cdot$ Dhaka

\section{Introduction}

Dhaka, the major city and central business hub of Bangladesh, is expanding at an alarming rate. The current urbanization level is around $30 \%$ and it is expected to rise to $50 \%$ by the year 2050 [29]. The city, which already hosts more than 15 million people, is currently the 11 th largest city in the world and attracts 300,000-400,000 new migrants every year from different parts of the country [38]. To meet the mobility demands of the rapidly growing population, the number of vehicles is increasing at an alarming rate. According to Bangladesh Road Transport Authority (BRTA), the number of newly registered vehicles in Dhaka in 2004 was 21,471 and has more than quadrupled over the next decade and reported to be 95,743 in 2015 [4].

Private cars hold the predominant share of these vehicles. According to BRTA, 127,632 private vehicles (cars, jeeps and station wagons) have been newly registered in Dhaka city against 9014 buses and minibuses in between 2004 and 2011 (Fig. 1). The trend of high private car to bus ratio reduced slightly in 2012 due to the ban in operating vehicles older than 20 years within Dhaka but then increased again (Fig. 2). Moreover, the occupancy rate of private vehicles is very low (reported to be 1.42 by Hasan [17]) which is leading to very inefficient use of the road space. This tremendous growth rate in private cars and their low occupancy levels have led to increasing traffic congestion levels. A recent 


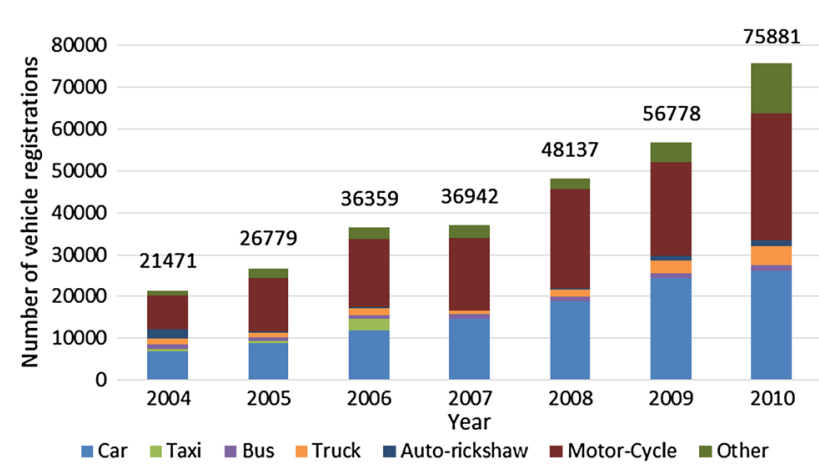

Fig. 1 Total number of newly registered vehicles in Dhaka [4]. Other includes ambulance, auto-tempo, cargo vehicles, special purpose vehicles, tankers and tractors

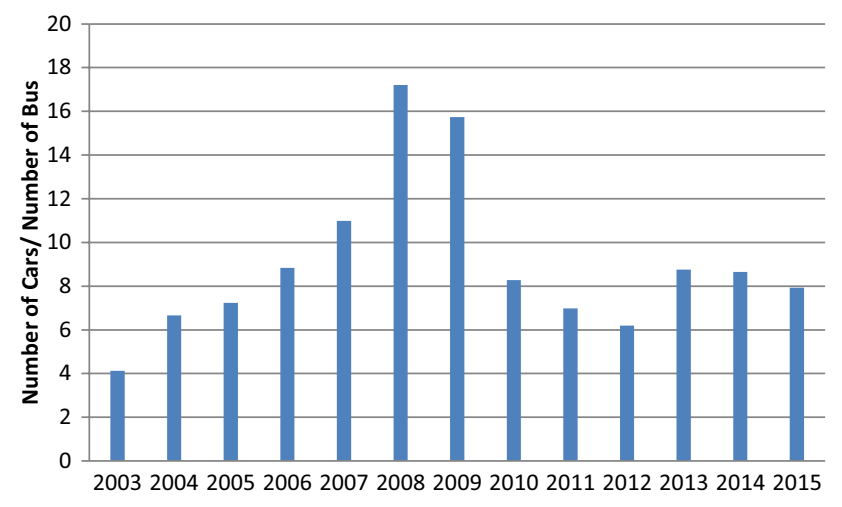

Fig. 2 Ratio of private cars and buses in Dhaka [4]

study by the Roads and Highways Department, Bangladesh has estimated that traffic congestion in Dhaka results a loss of 2.68 billion USD per year [37] which is more than half the country's total annual development outlay and one-fourth of the revenue collection target for that fiscal year. The study finds that about 3.2 million business hours are lost every day, which is about $1 \mathrm{~h}$ per working people. Increasing the physical capacity is however a very difficult option for the city with its high ratio of built-up areas (estimated to be $70 \%$ in Bari and Hasan [5]) and financial constraints. Therefore the solution of the problem requires increasing the operational capacity through improved demand and supply management.

Congestion pricing has emerged as one of the most effective regulatory measures against the severe traffic congestion problem in recent years which is already in effect in some major cities of the world like Singapore (1975), Rome (2001), London (2003), Stockholm (2006), Milan (2008), etc. Singapore introduced the world's first urban road pricing as an Area Licensing Scheme in 1975 which was upgraded to electronic road pricing (ERP) in 1998. It was found that traffic entering the central business district (CBD) during the morning peak in 1992 was about half the level before the scheme was introduced 17 years earlier. It was also found that average speeds had increased by $20 \%$ as well and accidents had fallen by $25 \%$ [25]. Moreover, modal share of public transport for working trips increased from 33\% in 1974 to $67 \%$ in 1992. The conversion of the Area License Scheme to the Electronic Road Pricing in 1998 resulted in more reduction (10-15\%) in the traffic volume in the CBD. London is another example of effective implementation of congestion pricing. According to the Transport for London [41] after introducing the congestion pricing in February 2003, London has immediate reduction of 24,700 cars during peak hours and $22 \%$ increase in traffic speed. The reductions in total traffic and car traffic in the congestion priced zone of $21 \mathrm{~km}^{2}$ were 16 and $30 \%$ respectively. Combined with an increase of bus and cycle traffic, this ultimately translated to a $32 \%$ reduction in delay per kilometre [41], though it did have a significant impact on the local businesses [28]. Stockholm has also experienced significant benefits: a $25 \%$ reduction in traffic volume and $30-50 \%$ reduction in queue time after the implementation of congestion pricing according to City of Stockholm Traffic Administration $[8,12]$. Interestingly, in Stockholm the scheme had not been favoured by the residents initially, but the clear improvements in traffic conditions have led to wider public acceptance. Tehran was the first developing country in the world to establish traffic restricted zone in CBD in 1979 which has been augmented by Automatic Number Plate Recognition (ANPR) technology in 2010. According to Tehran Traffic Control Company (TTCC), the city also experienced reduction in congestion and air pollution due to reduced private car usage [36]. It may be noted that though other car restriction policies, banning the cars on certain days of the week depending on license plate numbers (as implemented in Mexico in 1989 [11] in Beijing during the Olympic 2008 [33] and more recently in Delhi in 2016 [35] have made remarkable temporary improvements in congestion levels and air quality, but their long term feasibility is yet to be established [11]).

From the international experience regarding congestion pricing, it is evident that this regulatory measure has a good potential to be an effective solution to the chronic congestion problem in Dhaka. However, similar to other developing countries, the successful implementation of congestion pricing involves several challenges [24] including the lack of alternative modes to shift from private vehicles and the lack of public acceptance for the idea of paying charge for personal mobility. This has motivated this research where we have investigated the effectiveness of congestion pricing for two major types of trip: work trips (which include commute and business trips) and shopping trips. For each type of trip, separate case studies have been carried out to quantify the potential responses to congestion charging by executing 
stated preference (SP) surveys. In these surveys users have been presented with hypothetical choice scenarios involving varying amounts of congestion charges and travel time savings along with improved public transport options. Discrete choice models have been developed using the collected data.

It may be noted that though Dhaka is an old city (dating back to sixteenth century), very few travel demand models have been developed for the city so far. Among the previous models, Ahsan [2], DITS [10], Habib [16], STP [29], Hasan [17], DHUTS [9] and Enam and Choudhury [13, 14] are noteworthy. However, these models are either based on revealed preference (RP) data and/or focus on SP data with improved public transport options, and none of them have explored the potential response to congestion pricing or any other car restriction policy.

The rest of the paper is organized as follows: the overall data collection plan and descriptions of the case studies are presented first. The aggregate level analyses of the collected data are presented next which are followed by the model structure, estimation results and policy implications. The findings are summarized in the concluding section.

\section{Data and Methodology}

SP studies have been used to evaluate the potential response to congestion pricing by researchers in developed countries [23]. Examples include studies in Denmark [26], Germany [31], Greece [31], Italy [31], Norway [31], Japan [48], Netherlands (e.g. [3, 27, 32, 39, 42-47]), New Zealand [27], Portugal [49], United Kingdom (e.g. [15, 18-22, 30]). Among the developing countries, an SP survey to investigate acceptability and behavioural responses (e.g. modal switch) to congestion charging in Taiwan has been investigated (e.g. $[21,22])$. Review of these studies revealed the following key features [23]:

- Range of sample size: 94-1545.

- SP design method: fractional factorial design, efficient design.

- Model structure: multinomial logit, nested logit, mixed multinomial logit, ordered.

- Probit, tobit, regression, logistic regression.

- Number of SP tasks: 4-11.

- Purpose: commute, shopping, others.

- Potential response: departure time choice, modal shift, reduced car usage, change in work and/or residential location (in the long run).

The methodology of the current research has been based on the lessons learnt from these studies. However, geographic distinctions and differences in socio-demographics, attitudes and lifestyle have limited the transferability of the previous surveys and the congestion pricing scenarios and other alternative options presented to the respondents needed careful formulation grounded with local context.

In this research, the effect of congestion pricing has been investigated for two trip purposes: work (which includes commute and business) and shopping. Two separate case studies have been conducted in this regard among randomly selected car users via face-to-face interviews in car-parks. For shopping trips, a major shopping hub of the city: New Market, has been selected. For work trips, the congestion pricing scenario has been tested in the Motijheel, which is the central business district of the city. The locations are shown in Fig. 3. In each case, secondary data has been analyzed and initial surveys have been conducted to get an idea about the origin zones, current trip durations, costs and routes taken by the travellers. These have been used to construct the congestion charging scenarios and to formulate the available alternatives and associated levels of service in the SP scenarios. Travel times and costs (congestion charges) are varied for private cars in the SP scenarios for each case study. Since the concept of congestion charge is new to the respondents (and needed detailed explanation), the number of SP scenarios per respondent has been limited to two. The contact details of the respondents have been recorded for follow-up surveys (more detailed with additional $8 \mathrm{SP}$ scenarios), but yielded very small number of additional responses (less than $10 \%$ of the original respondents). The details of the survey design and data collection exercise for the two locations are presented below.

\section{Case Study I: Shopping Trips}

The New Market region, which is a major shopping hub of the city and a major traffic bottleneck, has been selected for testing the potential response to implement congestion charging in the context of shopping trips. New market has limited on and off-street parking facilities adjacent to the market which encourages users to use cars for their shopping trips. ${ }^{1}$

In order to construct the most effective schedule of the congestion charging, the existing patterns of traffic flow in the region was explored first using hourly traffic counts collected from the main access links to the area DHUTS [9]. As seen in Fig. 4a, the traffic flow in the region does not have distinct peaks and substantial congestion persists from $8 \mathrm{am}-8 \mathrm{pm}$ in the access links (which have three effective lanes each).Therefore, the option of changing time of travel

\footnotetext{
${ }^{1}$ It is now a requirement that all new shopping centres must provide sufficient number of off-street parking facilities in order to obtain planning permission and the on-street parking is illegal in the streets adjacent to most shopping facilities.
} 


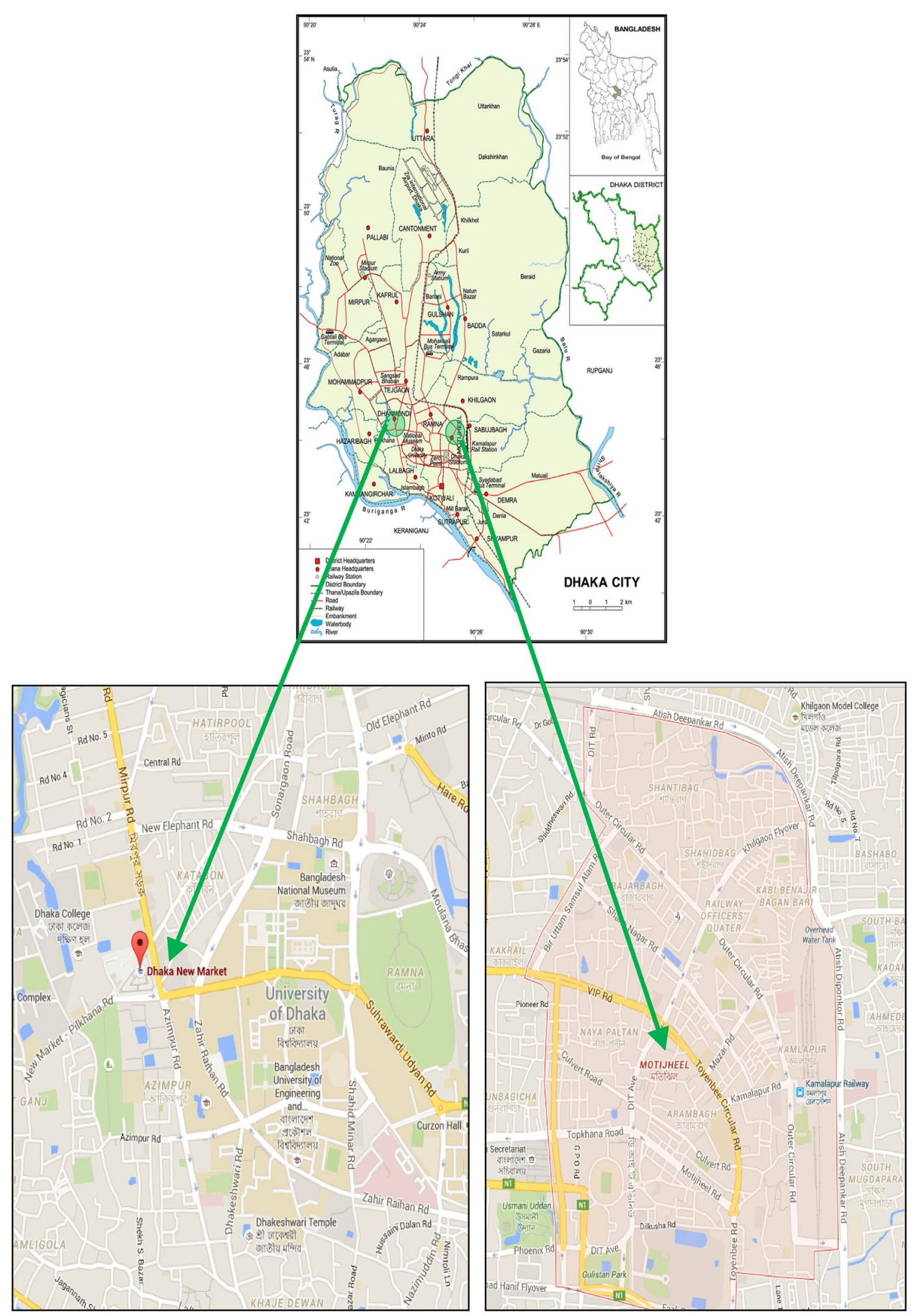

Fig. 3 Location of case studies. (Source: DHUTS [9] and Google, AutoNavi 2016) 


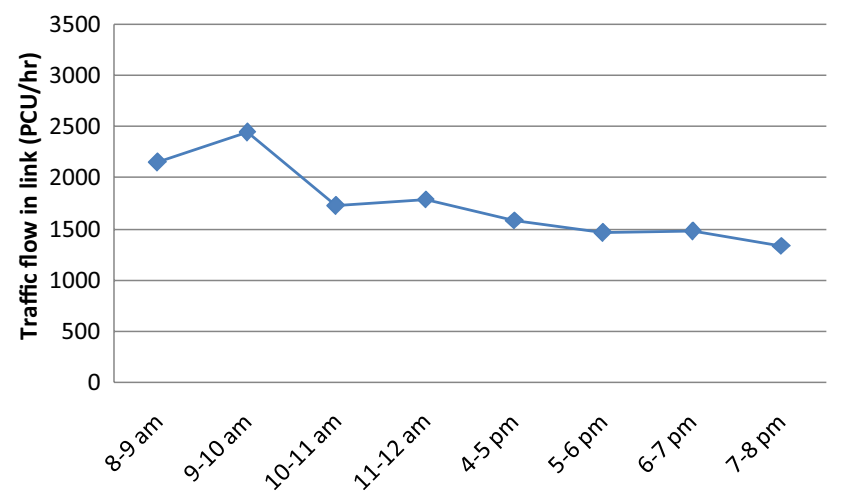

(a) New Market

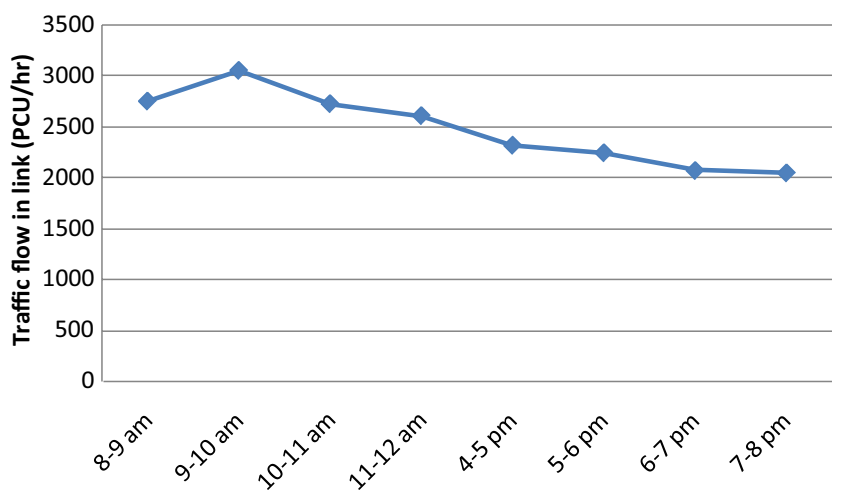

(b) Motijheel

Fig. 4 Time vs. flow graph in links connected to the study area (Data Source: DHUTS [9])

has not been included in the SP choice sets. Similarly, it has been assumed that eventually all major shopping areas will be subjected to congestion charge and for this reason, changing destination has not been considered as an alternative.

The SP survey has been conducted among randomly selected shoppers travelling by car using face-to-face interview technique. Care was taken to include the actual decision makers (as opposed to chauffeurs for instance) to replicate reality. The alternative modes presented to the respondents in this case included the following:

- Car (with congestion charge)

- Improved bus

- Park-and-ride.

For each of the respondents, the travel time and cost of the car presented in the SP scenarios were varied using the current travel time and travel costs as the base. The travel costs for the private car in the base case included fuel cost and off-street parking cost which were increased in the hypothetical scenario by adding a congestion charge to the road used for coming to the shopping district (Mirpur Road). Since congestion is expected to reduce due to introduction of the congestion charge, the travel times presented in the SP scenarios were lower than the current travel times. The Improved Bus service was described as an alternative with improved frequency, accessibility, cleanliness, safety and reliability. The arrangements of the Park-and-Ride facilities as well as their locations were described using pictures to make the alternatives clearer to the respondents (Fig. 5).

The respondents were allowed to choose their options after comparing the travel times and costs of the three alternatives. Different sets of values of travel time savings and travel costs were used depending on the duration of the current trip. Table 1 shows the time reductions and charges presented for different trip durations.
For improved bus and park-and-ride, it was assumed that travel time will decrease 15, 20 and 30 min from the current travel times for the short, medium and long trips respectively. It was explicitly mentioned that the Park-and-Ride will involve one additional transfer. The total travel costs by these modes were set as $20 \mathrm{BDT}, 20 \mathrm{BDT}$ and $30 \mathrm{BDT}$ for the three types of trip durations respectively. An orthogonal design considering the main effects was produced first using the statistical software SPSS [34]. Out of the 82 combinations, those containing unusual combinations and dominant choices, e.g. very low travel time savings for very high congestion charges or excessive travel time savings for little amount of charges were excluded and 21 reasonable combinations were retained. Two randomly selected combinations from this list were presented to each respondent.

In addition to the SP responses, data have been collected regarding the trip details (availability of other modes, reasons for using car, number of co-passengers, frequency of similar trips, etc.) and socio-economic characteristics (e.g. age, gender, income, occupation).

\section{Case Study II: Work Trips}

The Motijheel area, which is the central business district with the Headquarters of all major financial institutes, airlines, etc. and one of the most congested areas of Dhaka, has been selected for testing the potential response to congestion charge in the context of work trips (which include commute and business trips). It may be noted that during office hours, the effective width of the roads of this area are significantly reduced by legally or illegally parked vehicles along the main roads. A data collection plan similar to Case Study I has been used for this case and SP scenarios with appropriate levels were formulated based on the land-use pattern and the flow levels presented in Fig. 4b. It may be noted that given the initial origin-destination data for the work trips involved 

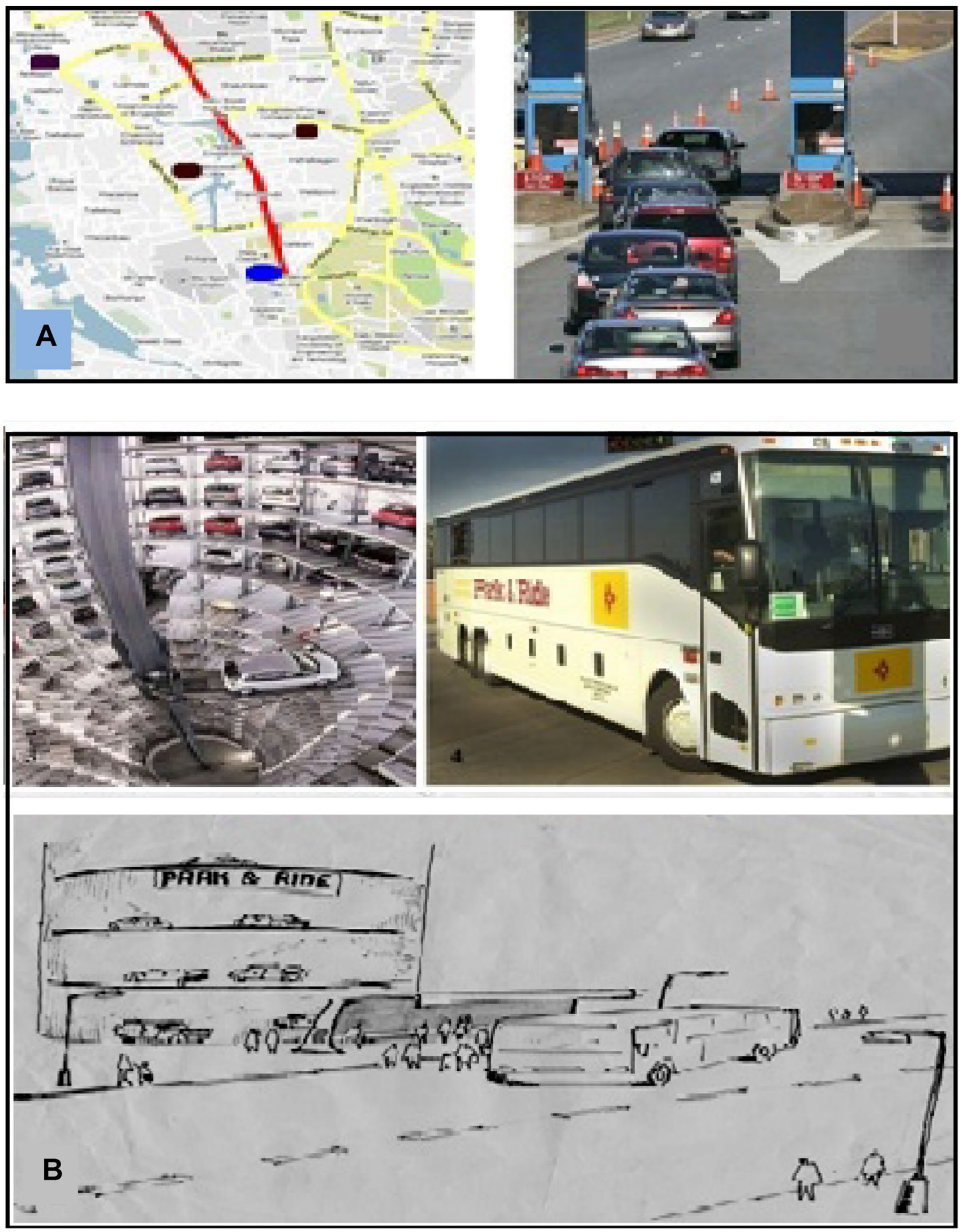

Fig. 5 Show cards for shopping trip: a location of charged link and congestion charge implementation, $\mathbf{b}$ park-and-ride 
Table 1 Congestion charge for each type of trip duration for shopping trips

\begin{tabular}{|c|c|c|c|c|c|}
\hline \multicolumn{2}{|c|}{ Short travel time (15-30 min) } & \multicolumn{2}{|c|}{ Medium travel time (30-60 min) } & \multicolumn{2}{|c|}{ Long travel time ( $>60 \mathrm{~min})$} \\
\hline $\begin{array}{l}\text { Travel time reduction } \\
\text { (min) }\end{array}$ & Charge (BDT) & $\begin{array}{l}\text { Travel time reduction } \\
\text { (min) }\end{array}$ & Charge (BDT) & $\begin{array}{l}\text { Travel time reduction } \\
\text { (min) }\end{array}$ & Charge (BDT) \\
\hline $5,8,12,15,20$ & $30,50,80,100,150$ & $10,12,15,20,25$ & $50,100,150,200,250$ & $12,20,25,30,40$ & $80,100,150,200,300$ \\
\hline
\end{tabular}

Table 2 Congestion charge for each type of trip duration for commute and business trips

\begin{tabular}{|c|c|c|c|c|c|}
\hline \multicolumn{2}{|c|}{ Short travel time (15-30 min) } & \multicolumn{2}{|c|}{ Medium travel time (30-60 min) } & \multicolumn{2}{|c|}{ Long travel time ( $>60 \mathrm{~min})$} \\
\hline $\begin{array}{l}\text { Travel time reduction } \\
\text { (min) }\end{array}$ & Charge (BDT) & $\begin{array}{l}\text { Travel time reduction } \\
\text { (min) }\end{array}$ & Charge (BDT) & $\begin{array}{l}\text { Travel time reduction } \\
\text { (min) }\end{array}$ & Charge (BDT) \\
\hline $10,12,15,18,20$ & $50,70,100,150,180$ & $12,15,20,25,30$ & $\begin{array}{l}100,150,200,250, \\
300\end{array}$ & $15,20,25,30,40$ & $200,250,300,350,400$ \\
\hline
\end{tabular}

much diverse origins compared to the shopping trips, it was very complicated to identify suitable parking lots for park and ride options. Therefore, hypothetical Off-street Car Parking Facilities, described as facilities that may not be directly adjacent to the destination (and replaces the current free/low-cost on-site parking in the Motijheel area) have been presented in the SP scenarios of Case Study II instead of the park-and-ride alternative presented in Case Study I. In the hypothetical scenario, travellers have the option to park their cars in an off-street location: not adjacent, but close to their destination and walk the rest of the way, rather than using a bus from a distant parking lot (which as mentioned was difficult to define as well due to the diverse origins). The choice set in this case therefore included the following:

- Car (with congestion charge)

- Improved bus

- Off-street parking.

Similar to the previous case study, the trip durations were classified as short, medium and long and travel times and costs were varied accordingly. The findings of the initial survey however revealed longer trip durations in this case compared to Case Study I which was not unexpected. Moreover, because of the higher levels of congestion and lower physical capacities, the presented congestion charges were higher compared to Case Study I. Table 2 shows the time reductions and charges used in the SP scenarios for different trip durations. As in Case Study I, due to consistent level of congestion from 8 am- $8 \mathrm{pm}$ and the lack of flexibilities in the working hours in the offices, respondents were not given the option to change their departure times.

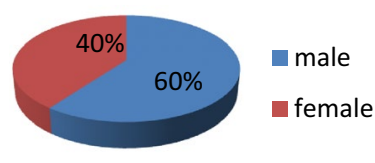

(a) Gender: Shopping Trip
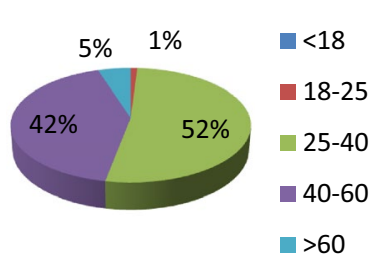

(c) Age (years) : Shopping Trip

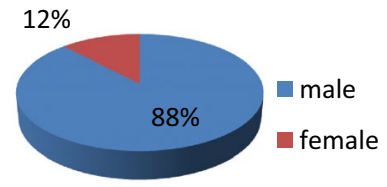

(b) Gender: Work Trip

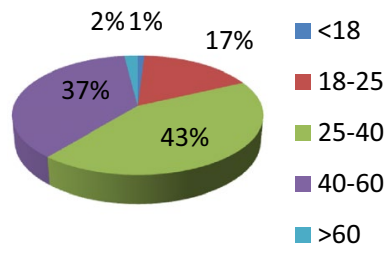

(d) Age(years): WorkTrip
Fig. 6 The distribution of socio-economic characteristics

The questionnaire survey has been conducted in a similar way as the previous case study in order to maintain similarity and compatibility between the two.

\section{Data}

A total of 228 and 132 respondents participated in Case Study I and II respectively. Each respondent have been presented with two SP scenarios, so the total number of responses were 456 and 264 respectively. An additional 240 responses have been collected by follow-up phone surveys (where each respondent have been presented with 8 additional SP scenarios). The socio-demographics of the respondents have been presented in Fig. 6. As seen in the figure, the samples (especially for the Work trip) had an over representation of male respondents. This is however not unexpected given the male dominance in the white 


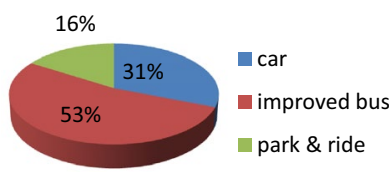

(a) Shopping Trip

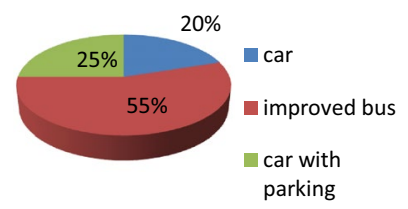

(b) Work Trip
Fig. 7 SP mode choices

collar work force. Similarly, majority of the respondents in the sample were between 25 and 60 years which is also a representation of the reality (most of the car travellers making shopping and work trips are expected to belong to this group). It may be noted that all the respondents were educated at least up to Higher Secondary (Grade 12) and majority of them used their own cars (rather than cars provided from their offices). Almost all the respondents had chauffeurs.

All the respondents had the opportunity to use other modes for their respective trips. When asked about reasons for choosing car for their trips, majority of the people (65\%) have listed safety and comfort as the principal reasons. Moreover, convenience to reach the destination directly was also a dominant factor (cited by $25 \%$ of the respondents). They had not used the bus due to the unacceptable environment of the bus service (crowding, lack of safety and security, unclean interior) and accessibility problems to the bus from their origin.

In the SP scenarios, significant shift to improved bus services has been observed (Fig. 7). This trend has been found to be more prominent (more than 34\%) for middle income people with income ranging from 50,000 to 75,000 BDT.

\section{Model Development}

Discrete choice model structures (see $[6,40]$ for details) have been used to establish relationships between the chosen alternatives and the explanatory variables. The variables included trip attributes (e.g. trip duration, travel time, cost, purpose, etc.) and socio-economic characteristics (e.g. age, income, gender, number and age of co-travellers, etc.). Due to the SP question setting, the potential difference in sensitivity among different forms of cost: congestion charge, parking fee and bus fare has also been explored. The candidate socio-economic characteristics and trip attributes likely to affect the sensitivities towards cost increases and time savings are presented in Table 3.

The data consisted of two observations from each respondent. multinomial logit model (MNL) with a panel formulation (that accounts for the correlation of error terms of responses from the same respondent) has been used here to estimate the utility parameters of different choices in the choice set. The utility of choice $i$ of individual $n$ can be expressed as follows:

$U_{i n}=\beta_{i} X_{i n}+\vartheta_{n}+\varepsilon_{i n}, \quad \forall i \in C_{n}$

where, $X_{i n}=$ socio-economic characteristics of the individuals and attributes of different modes, $\beta_{i}=$ Coefficient of $X_{i n}, \vartheta_{n}=$ Individual specific error term, $\varepsilon_{i n}=$ Random error term and $C_{n}=$ Available set of modes (Choice set) presented to individual $n$.

The probability of individual $n$, choosing alternative $i$ can be expressed as follows:

$P_{i n} \mid \vartheta_{n}=\frac{e^{\beta_{i} X_{i n}}}{\sum_{j} e^{\beta_{j} X_{j n}}}, \quad i, j \in C_{n}$

Table 3 Candidate variables and usual choice relationship

\begin{tabular}{|c|c|}
\hline Attributes & General casual relationship \\
\hline Monthly income & $\begin{array}{l}\text { The people with higher income are likely to be less sensitive to cost and may prefer to use car in spite of the } \\
\text { imposed charge }\end{array}$ \\
\hline Age & $\begin{array}{l}\text { Old people are likely to have higher propensity to use car with congestion charge for its better accessibility and } \\
\text { level of comfort }\end{array}$ \\
\hline Gender & $\begin{array}{l}\text { Due to social norms and culture, female passengers often do not feel comfortable riding buses with male co- } \\
\text { passengers (especially in congested situations) and tend to avoid bus due to safety and privacy concerns. Female } \\
\text { respondents are therefore more likely to opt for car and park-and-ride }\end{array}$ \\
\hline Travel duration & $\begin{array}{l}\text { Travellers are more likely to favour bus for longer trips since access time is a smaller portion of the total travel } \\
\text { time in those cases }\end{array}$ \\
\hline Occupation & $\begin{array}{l}\text { White-collar employees are likely to have higher propensities of using cars. Housewives of higher income groups } \\
\text { may also have additional inclination to use car }\end{array}$ \\
\hline Accompanying persons & $\begin{array}{l}\text { Travellers are more likely to use cars if they are travelling in a group. In particular, if there are children and } \\
\text { elderly members in the group, there may be added propensity to use cars }\end{array}$ \\
\hline Parking perk (for work trips) & $\begin{array}{l}\text { If the parking space and/ or charge are currently provided by the employer, there may be added propensity to opt } \\
\text { for off-street paid parking facilities }\end{array}$ \\
\hline
\end{tabular}


Table 4 Estimation results of the individual models

\begin{tabular}{|c|c|c|c|c|c|c|}
\hline \multirow[t]{2}{*}{ Parameter } & \multirow[t]{2}{*}{ Variable definition } & \multicolumn{2}{|l|}{ Shopping } & \multicolumn{2}{|l|}{ Commute } & \multirow[t]{2}{*}{$t$ stat difference } \\
\hline & & Estimated value & Robust $t$ stat & Estimated value & Robust $t$ stat & \\
\hline ASC_BUS & Alternative specific constant for bus & 0.00 & - & 0.00 & - & \\
\hline ASC_CAR & Alternative specific constant for car & 0.14 & 0.26 & 0.93 & 1.78 & -2.24 \\
\hline ASC_PR & $\begin{array}{l}\text { Alternative specific constant for park } \\
\text { and ride }\end{array}$ & -1.17 & -8.86 & & & - \\
\hline ASC_OP_CT & $\begin{array}{l}\text { Alternative specific constant for off- } \\
\text { street parking }\end{array}$ & & & 2.52 & 2.83 & - \\
\hline$\beta_{\text {COST_HIGH_INC }}$ & $\begin{array}{l}\text { Cost of travel for high income } \\
\text { respondents ('00 BDT) }\end{array}$ & -3.40 & -2.41 & -1.90 & -4.34 & 0.64 \\
\hline$\beta_{\text {COST_MID_INC }}$ & $\begin{array}{l}\text { Cost of travel for middle income } \\
\text { respondents ('00 BDT) }\end{array}$ & -4.33 & -2.63 & -2.40 & -5.35 & 0.60 \\
\hline$\beta_{\text {COST_LOW_INC }}$ & $\begin{array}{l}\text { Cost of travel for low income } \\
\text { respondents ('00 BDT) }\end{array}$ & -6.72 & -1.69 & -3.08 & -5.38 & -0.33 \\
\hline$\beta_{\text {SHARE }}$ & $\begin{array}{l}\text { Dummy for trips shared with co- } \\
\text { passengers, } 1 \text { if shared, } 0 \text { otherwise }\end{array}$ & - & - & -1.04 & -2.74 & - \\
\hline$\beta_{\text {TIME_SAVING }}$ & Travel time saving (hours) & 1.19 & 1.41 & 3.13 & 1.77 & -0.30 \\
\hline$\beta_{\text {PARKING }}$ & $\begin{array}{l}\text { Dummy for availability of parking } \\
\text { perk from office, } 1 \text { if available, } 0 \\
\text { otherwise }\end{array}$ & - & - & 1.68 & 3.23 & - \\
\hline$\sigma_{n}$ & Panel effect & 2.16 & 3.73 & 2.78 & 0.11 & 0.08 \\
\hline Number of observations & & 496 & & 464 & & \\
\hline Number of individuals & & 228 & & 132 & & \\
\hline Number of parameters & & 7 & & 9 & & \\
\hline Null log-likelihood & & -500.97 & & -290.03 & & \\
\hline Final log-likelihood & & -439.58 & & -195.88 & & \\
\hline Adjusted rho-sqr & & 0.169 & & 0.294 & & \\
\hline
\end{tabular}

The likelihood function of observing the choices of individual $n$, conditional on the individual specific error term $\vartheta_{n}$ can be expressed as follows:

$\prod_{i}\left(P_{i n} \mid \vartheta_{n}\right)^{y_{n i}}$

where $y_{n i}=1$ if person $n$ chooses alternative $i, 0$ otherwise.

Since each respondent's choice is independent of the choices of the other respondents, the likelihood of the observed choices are as follows:

$L\left(\beta \mid \vartheta_{n}\right)=\prod_{n} \prod_{i}\left(P_{n} \mid \vartheta_{n}\right)^{y_{n i}} \mathrm{f}(\vartheta) \mathrm{d} \vartheta$

The log-likelihood function is then

$L L\left(\beta \mid \vartheta_{n}\right)=\sum_{n} \sum_{i}\left(P_{i n} \mid \vartheta_{n}\right)^{y_{n i}} \mathrm{f}(\vartheta) \mathrm{d} \vartheta$

The unconditional probabilities can be derived by integrating this over the distribution of the individual specific error term:

$$
\int_{\vartheta} L L\left(\beta \mid \vartheta_{n}\right) \mathrm{f}(\vartheta) \mathrm{d} \vartheta
$$

The individual specific error term capturing the panel effect is assumed to be normally distributed $\vartheta_{n} \sim \mathrm{N}\left[0, \sigma_{n}^{2}\right]$ and the model parameters ( $\beta$ and $\sigma_{n}$ ) are estimated by maximizing this function using the software BIOGEME [7]. The effects of different candidate variables have been tested and the variables with correct signs and reasonable statistical significance have been included in the final model which is presented in the next section.

\section{Estimation Results}

Since the choice-set was different in the two case studies and there may be differences in sensitivities across the trip purposes, separate models have been developed first for shopping and work trips. However, transferability of the model parameters between the two scenarios have been checked to statistically test whether or not there is a significant difference between the parameter estimates of the equivalent variables. This ultimately led to the development of a pooled model. The results of the separate and 
Table 5 Estimation results of the pooled model

\begin{tabular}{|c|c|c|c|c|}
\hline Parameter & Variable definition & Affected alternatives (type of the trip) & Estimated value & Robust t-stat \\
\hline ASC_BUS_ST & Alternative specific constant for bus & BUS (ST) & 0.000 & - \\
\hline ASC_BUS_CT & Alternative specific constant for bus & BUS (CT) & 0.000 & - \\
\hline ASC_CAR_ST & Alternative specific constant for car & Car with congestion pricing (ST) & 0.651 & 1.75 \\
\hline ASC_CAR_CT & Alternative specific constant for car & Car with congestion pricing (CT) & 0.777 & 1.64 \\
\hline ASC_PR_ST & Alternative specific constant for park and ride & Park and ride (ST) & -1.170 & -6.85 \\
\hline ASC_OP_CT & Alternative specific constant for off-street parking & Car with parking facilities (CT) & 2.280 & 2.83 \\
\hline$\beta_{\text {COST_HIGH_INC }}$ & $\begin{array}{l}\text { Cost of travel for middle income respondents (' } 00 \\
\text { BDT) }\end{array}$ & All available mode & -1.820 & -4.83 \\
\hline$\beta_{\text {COST_MID_INC }}$ & Cost of travel for low income respondents ('00 BDT) & All available mode & -2.350 & -5.91 \\
\hline$\beta_{\text {COST_LOW_INC }}$ & $\begin{array}{l}\text { Dummy for trips shared with co-passengers, } 1 \text { if } \\
\text { shared, } 0 \text { otherwise }\end{array}$ & All available mode & -2.890 & -5.63 \\
\hline$\beta_{\text {SHARE }}$ & Travel time saving (hours) & Bus $(\mathrm{CT})$ & -1.030 & -2.69 \\
\hline$\beta_{\text {TIME_SAVING }}$ & Travel time saving & All available mode & 2.298 & 1.40 \\
\hline$\beta_{\text {PARKING }}$ & $\begin{array}{l}\text { Dummy for availability of parking perk from office, } 1 \\
\text { if available, } 0 \text { otherwise }\end{array}$ & Car with parking facilities (CT) & 1.690 & 3.27 \\
\hline$\sigma_{n}$ & Panel effect & All available mode & 2.550 & 5.42 \\
\hline
\end{tabular}

$S T$ shopping trip, $C T$ commuter and business trip, $C P$ congestion pricing

pooled models are presented in Tables 4 and 5 respectively and described in the following sections.

\section{Case Study I: Shopping Trips}

The trip attribute variables tested in for the shopping trip model included cost increase (congestion charge) and travel time savings. The potential difference of these variables across different age, income, occupation and gender groups. The taste heterogeneity across the age, gender and occupation has not found to be statistically significant for time or cost. However, the sensitivity to congestion charge has been found to vary significantly across different income groups. The potential difference in sensitivity among different forms of cost: congestion charge, parking fee and bus fare has also been explored but not found to be significant. The sensitivity to these factors for different trip duration (short, medium, long) has also been investigated but not found to be significant which may be due to the fact that majority of the shopping trips (87.\%) were short or medium (less than an hour).

Estimation results revealed that all else being equal, travellers do prefer car but the coefficient is not significantly different from zero at $90 \%$ level of confidence. However, all else being equal, the park-and-ride alternative was found to be significantly less preferred compared to improved bus.

The alternative constant terms were not found to be significantly different among different income groups. However, travellers with high household income (more than 75,000 BDT per month) are found to be less sensitive to congestion pricing compared to the medium (more than 50,000-75,000 BDT per month) and lower income people (less than 50,000 per month). ${ }^{2}$ The cost sensitivity has been found to be statistically significant at $95 \%$ level of confidence for high and medium income groups only with the confidence level dropping to $90 \%$ for work trips.

Sensitivity to travel time savings is found to be less than sensitivity to cost increase (which is similar to the trend found in previous demand models developed for public transport studies e.g. by Enam and Choudhury [14]). Significant inter-respondent heterogeneity in the error terms has been observed.

\section{Case Study II: Work Trips}

The estimation results of the model for commute/work trips are found to follow similar trends as shopping trips. The inertia to use car has been found to be slightly more than shopping trips and statistically significant at $90 \%$ level of confidence (but still not statistically significant at $95 \%$ level of confidence). Interestingly, the alternative specific constant for off-street car parking has been found to be higher than improved bus service (and statistically significant at $95 \%$ level of confidence) indicating that all else being equal, travellers significantly prefer this option over all other alternatives.

The sensitivity to cost was found to follow a similar trend across different income groups-the sensitivity being lower

\footnotetext{
${ }^{2}$ Note that the low, medium and high income groups are relative groupings within the car users and not identical to the groups used in generic transport studies in Dhaka which includes non-car users as well many of them having income less than 50,000 BDT.
} 
for medium and higher income groups. Pairwise comparisons of the cost sensitivities of each income group between the two case studies indicate that the cost sensitivity is slightly higher in case of the shopping trips, though the differences in the magnitudes are not found to be statistically significant.

The sensitivity to travel time savings is found to be higher for work trips compared to the corresponding values of Case Study I and though the magnitude of the coefficient is higher than the sensitivity to the cost parameters, it is statistically significant only in $90 \%$ level of confidence.

As in the shopping trips, the taste heterogeneity across gender, occupation, age and trip duration has not been found to be statistically significant. However, two additional variables were found to have significant effects in case of the work trips. Firstly, travellers were found to be less inclined to shift from car if they have co-passengers during their commute. Secondly, they are found to be significantly less inclined to shift from car or if they currently receive parking perks from the office. The inter-respondent heterogeneity in the error terms has not been found to be statistically significant but has been retained for the ease of model comparison.

\section{Pooled Model}

Parameter transferability tests have been conducted to test whether or not there is a significant difference between the parameter estimates of equivalent variables in the two casestudies (Eq. 7). Minimum and maximum $t$ ratio values of -1.96 and 1.96 corresponding to the $95 \%$ confidence are taken as the critical values.

$t_{d i f f, k}=\frac{\beta_{S T, k}-\beta_{C T, k}}{\sqrt{\left(\frac{\beta_{S T, k}}{t_{S T, k}}\right)^{2}+\left(\frac{\beta_{C T, k}}{t_{C T, k}}\right)^{2}}}$

where $\beta_{S T, k}$ and $\beta_{C T, k}$ are the estimates for the $k$-th parameter for the shopping and work trips respectively and $t_{S T, k}$ and $t_{C T, k}$ are the respective $t$ ratios of the parameter estimates, and $t_{\text {diff }, k}$ is the $t$ ratio for the difference between parameters.

Interestingly, the pairwise comparison of the coefficients indicated other than the Alternate Specific Constants, the difference between the coefficients are not statistically significant between the two case studies which motivated the development of a pooled model where only the Alternative Specific Constants were assumed to be different and the sensitivity to the cost and time variables are assumed to be generic across the shopping and the work trips.

The estimation results of the pooled model (Table 5), similar to the separate models, indicate that all else being equal, car with congestion charge is not significantly preferred over improved bus service. The park-and-ride (for shopping trips) are significantly less preferable and off-street parking (for work trips) are significantly more preferred compared to the improved bus (all else being equal).

Travellers with high household income (more than 75,000 BDT per month) are found to be less sensitive to congestion pricing compared to the medium $(50,000-75,000$ BDT per month) and lower income people (less than 50,000 per month). Sensitivity to travel time savings is, however, less than sensitivity to cost increase (which is similar to the trend found in previous demand models developed for public transport studies e.g. by Enam and Choudhury [14]). The estimated cost and time coefficients indicate an average value of time (VOT) of $101.19 \mathrm{BDT} / \mathrm{h}$. It may be noted the VOT derived from an RP study conducted around the same period reported VOT to be $106.80 \mathrm{BDT} / \mathrm{h}$ [13]. The similarities in the values serve as an indirect validation of the current study.

Travellers are less inclined to shift from car if they have co-passengers during their commute or if they currently receive parking perks from the office. Significant inter-respondent heterogeneity in the error terms has been observed.

It may be noted that statistical tests revealed that there are no significant scale differences between the two case studies.

\section{Concluding Remarks}

The potential response to implementation of congestion charging in Dhaka has been explored in this research. The study has several limitations though. In particular, the data sizes are relatively small and collected from two selected locations. Similar case studies need to be repeated in other parts of the city and for other types of trips (e.g. social trips, recreational trips, etc.) to get more representative results. Moreover, in order to keep the choice task simple, the levels of services for the non-car alternatives have been kept fixed in this research. Varying the levels of services of those alternatives can help in reducing standard errors and subsequently to improve the statistical significance of the parameter.

The research, though limited in extent, provides important behavioural insights that need to be considered to implement congestion charging successfully in Dhaka. The key policy implications are listed below.

- It can be inferred from the aggregate analysis that congestion pricing can play an effective role in shifting travellers from cars when they are provided with the option to use public transport with improved levels of service. This is also inline with their feedback regarding reasons for using car. Therefore, proper emphasis 
must be given in improving levels of service of public transport before congestion charging is implemented. Part of this investment can be recovered later by the revenue generated from the congestion charge.

- The modelling results revealed that travellers have significant sensitivity to cost increases which is also a promising indication about the potential effectiveness of congestion pricing in the city. However, the highest income group (who have the highest usage rates of cars and have higher average trip lengths [9]) were found to be less sensitive to the congestion charges. This needs to be accounted for in the detailed feasibility study so that the reduction in traffic is not overestimated.

- Travellers were found to be less inclined to shift from car if they receive parking perks (e.g. free parking spots) from the office. In order to increase the efficacy of congestion pricing, these kinds of incentives need to be abolished and/or replaced by public transport usage perks (e.g. subsidized public transport passes).

In general, the fact that the results of the two models representing two locations of Dhaka city focusing on two different trip purposes are identical (in spite of the relatively small data sizes) is very encouraging. The coefficients of the model informs the sensitivity to different relevant factors and variations across socio-demographics while the willingnessto-pay the congestion charge (or the lack thereof) can serve as a guidance for setting the optimum ranges of the congestion price. These findings can thus serve as a useful tool for the traffic planners of Bangladesh to stall the rapid increase of cars, foster usage of more sustainable travel modes and subsequently improve the traffic condition in Dhaka.

Open Access This article is distributed under the terms of the Creative Commons Attribution 4.0 International License (http://creativecommons.org/licenses/by/4.0/), which permits unrestricted use, distribution, and reproduction in any medium, provided you give appropriate credit to the original author(s) and the source, provide a link to the Creative Commons license, and indicate if changes were made.

\section{References}

1. Agrawal AW, Nixon H (2011) What do Americans think about federal transportation tax options? Results from a national survey. Paper Presented at 90th Transportation Research Board Annual Meeting. January, Washington, D.C., United States

2. Ahsan HM (1990) Study of mass transit in metropolitan Dhaka. M.Sc. Engg. Thesis, Department of Civil Engineering, Bangladesh University of Engineering and Technology, Dhaka

3. van Amelsfort D, Bovy PHL, Bliemer MCJ, Ubbels B (2008) Travellers' responses to road pricing: value of time, schedule delay and unreliability. In: Verhoef ET, Bliemer MCJ, Steg L, van Wee B (eds) Pricing in road transport: a multi-disciplinary perspective. Edward Elgar, Northampton, pp 64-85
4. BRTA (2016) Registered vehicles in Dhaka. http://www.brta.gov. bd/statistics.php. Accessed Oct 2016

5. Bari MF, Hasan M (2001) Effect of urbanization on storm runoff characteristics of Dhaka City. Tsinghua University Press, XXIX IAHR Congress, Beijing

6. Ben-Akiva ME, Lerman SR (1985) Discrete choice analysis: theory and application to travel demand. MIT Press series in transportation studies, USA

7. Bierlaire M (2003) BIOGEME: a free package for the estimation of discrete choice models. In: Proceedings of the 3rd Swiss Transport Research Conference, Monte Verita

8. Borjesson M, Eliasson J, Besehugosson M, Brundell K (2010) The Stockholm congestion charges-four years on. Effects, acceptability and lessons learnt, centre for transport studies, Royal Institute of Technology, Stockholm

9. DHUTS (2010) Dhaka urban transport network development study, draft final report. Katahira and Engineers International, Oriental Consultants Co. Ltd., and Mitsubishi Research Institute, Inc, Japan

10. DITS (1993) Greater Dhaka metropolitan area integrated transport study. PPK Consultants Declan International and Development Design Consultant (DDC), Dhaka

11. Davis LW (2008) The Effect of driving restrictions on air quality in Mexico City (PDF). J Polit Economy 116(1):38-81

12. Eliasson J, Hultkrantz L, Nerhagen L, Rosqvist LS (2009) The Stockholm congestion-charging trial 2006: overview of effects. Transp Res Part A Policy Pract 43(3):240-250

13. Enam A, Choudhury C (2011) Methodological issues in developing mode choice models for Dhaka, Bangladesh. Transp Res Rec: J Transp Res Board 2239:84-92

14. Enam A, Choudhury C (2013) A comprehensive model to capture the preference for mass rapid transit in Dhaka. In Hess S, Daly A (eds) Choice modelling: the state of the art and the state of practice. Edward Elgar, UK

15. Farrell S, Saleh W (2005) Road-user charging and the modelling of revenue allocation. Transp Policy 12(5):431-442

16. Habib KMN (2002) Evaluation of planning options to alleviate traffic congestion and resulting air pollution in Dhaka City. M.Sc. Thesis, Department of Civil Engineering, Bangladesh University of Engineering and Technology, Dhaka

17. Hasan S (2007) Development of a travel demand model for Dhaka City, M.Sc. Thesis, Department of Civil Engineering, Bangladesh University of Engineering and Technology, Dhaka

18. Hu S, Saleh W (2005) Impacts of congestion charging on shopping trips in Edinburgh. Transp Policy 12(5):443-450

19. Jaensirisak S, May AD, Wardman M (2003) Acceptability of road user charging: the influence of selfish and social perspectives. In: Schade J, Schlag B (eds) Acceptability of transport pricing. Elsevier Science, Oxford, pp 203-218

20. Jaensirisak S, Wardman M, May AD (2005) Explaining variations in public acceptability of road pricing schemes. J Transp Econ Pol 39(2):127-153

21. Jou RC, Hensher DA, Wu PH, Fujii S (2010) Road pricing acceptance: analysis of survey results for Kyoto and Taichung. Int J Sustain Transp 4(3): 172-187

22. Jou RC, Lam SH, Wu PH (2007) Acceptance tendencies and commuters' behavior under different road pricing schemes. Transportmetrica 3(3):213-230

23. Li Z, Hensher D (2012) Congestion charging and car use: a review of stated preference and opinion studies and market monitoring evidence. Transp Policy 20:47-61

24. Mahendra A (2008) Congestion pricing in cities of the developing world: exploring prospects in Mexico City, MCP and MST Thesis, Department of Urban Studies and Planning, Massachusetts Institute of Technology, Dhaka 
25. May AD, Sumalee A (2003) One step forwards, two steps back? An overview of road pricing application and research outside the US. In: International Symposium on Road Pricing, Key Biscayne, Florida, Institute for Transport Studies, University of Leeds, England, pp 7, 12-14

26. Nielsen OA (2004) Behavioural responses to road pricing schemes: description of the Danish AKTA experiment. Intell Transp Syst 8:233-251

27. O'Fallon C, Sullivan C, Hensher DA (2004) Constraints affecting mode choices by morning car commuters. Transp Policy 11(1):17-29

28. Quddus MA, Bell M.G.H., Schmocker J, Fronzone A (2007) The impact of the congestion charge on the retail businessin London: an econometric analysis. Transp Policy 14:433-444

29. STP (2005) Strategic transport plan for Dhaka. Louis Berger Group and Bangladesh Consultant Ltd, Bangladesh

30. Saleh W, Farrell S (2005) Implications of congestion charging for departure time choice: work and non-work schedule flexibility. Transp Res Part A 39(7):773-791

31. Schade J, Schlag B (2003) Acceptability of urban transport pricing strategies. Transp Res Part F 6(1):45-61

32. Schuitema G, Ubbels B, Steg L, Verhoef ET (2008) Car users' acceptability of a kilometre charge. In: Verhoef ET, Bliemer MCJ, Steg L, van Wee B (eds) Pricing in road transport: a multi-disciplinary perspective. Edward Elgar, Northampton, pp 209-226

33. Shen J, Tang A, Liu X, Kopsch J, Fangmeier A, Goulding K, Zhang F (2011) Impacts of pollution controls on air quality in Beijing during the 2008 Olympic Games. J Environ Qual 40(1):37-45

34. SPSS Inc (2007) SPSS for windows, version 16.0. Chicago: SPSS Inc

35. Subramanian M (2016) New Delhi car ban yields trove of pollution data. Nature 530(7590):266-267

36. Tehran Traffic Control Company (TTCC) (2012) http://www.tehran-congestion-charging.ir/English/details. aspx ?type $=$ B \&id $=559$. Accessed Nov 2012

37. The Daily Star (2010) Online version. http://www.thedailystar.net/ newDesign/news-details.php?nid=147756. Accessed Nov 2010
38. The World Bank (2007) Dhaka: improving living conditions for the urban Poor. Bangladesh Development Series, Paper No. 17, Dhaka

39. Tillema T, van Wee B, Ettema D (2010) Road pricing and relocation decisions of Dutch households. Urban Stud 47:3013-3033

40. Train K (2003) Discrete choice methods with simulation. Cambridge University Press, Cambridge

41. Transport for London (TfL) (2004) C-Charge annual report. http:// www.tfl.gov.uk/static/corporate/ media/newscentre/archive/4339. html. Accessed Oct 2010

42. Tseng Y, Verhoef ET (2008) Value of time by time of day: a stated preference study. Transp Res Part B 42:607-618

43. Tseng Y, Ubbels B, Verhoef ET (2005) Value of time, schedule delay and reliability - estimation based on choice behaviour of Dutch commuters facing congestion. Paper Presented at the 45th ERSA Congress. VU University, Amsterdam

44. Ubbels B, Tillema T, Verhoef ET, vanWee GP (2008) Effects of a kilometre charge on car use,car ownership and relocation. In: Verhoef ET, Bliemer MCJ, Steg L, van Wee B (eds) Pricing in road transport : a multi-disciplinary perspective. Edward Elgar, Northampton, pp 86-105

45. Ubbels B, Verhoef ET (2005) Behavioural responses to road pricing: empirical results from a survey among Dutch car owners. Eur TransplTrasporti Europei 31:101-117

46. Ubbels B, Verhoef ET (2006) Behavioural responses to road pricing :empirical results from a survey among Dutch car owners. Transp Res Rec 1960:159-166

47. Ubbels B, Verhoef ET (2006) Acceptability of road pricing and revenue use in The Netherlands. Eur Transp\Trasporti Europei 32:69-94

48. Yamamoto T, Fujii S, Kitamura R, Yoshida H (2000) Analysis of time allocation, departure time, and route choice behavior under congestion pricing. Transp Res Rec 1725:95-101

49. Yang L, Choudhury C, Ben-Akiva M, Abreu J (2009) Modeling preference for innovative modes in Lisbon: a stated preference approach. In: European Transport Conference 